SOUILLJEE, Liege Giaretta. Direitos Humanos e Transnacionalidade: um debate sobre as pretensões jurídicas globalizadas. Revista Eletrônica Direito e Política, Programa de Pós-Graduação Stricto Sensu em Ciência Jurídica da UNIVALI, Itajaí, v.12, n.3, 30 quadrimestre de 2017. Disponível em: www.univali.br/direitoepolitica - ISSN 1980-7791

\title{
DIREITOS HUMANOS E TRANSNACIONALIDADE: UM DEBATE SOBRE AS PRETENSÕES JURÍDICAS GLOBALIZADAS
}

\author{
HUMAN RIGHT AND TRANSNATIONALITY: A DEBATE ABOUT THE GLOBAL LEGAL
}

CLAIMS

\author{
Liege Giaretta Souilljee ${ }^{1}$
}

\section{RESUMO}

O presente artigo tem como objetivo correlacionar alguns aspectos do temário geral dos Direitos Humanos com a transnacionalidade, com o princípio da Dignidade da pessoa humana e com o intercâmbio das decisões judiciais entre os países. Longe da pretensão de trazer respostas últimas ao tema, a pesquisa identifica os Direitos Humanos como critério de união juridicamente considerado na sociedade globalizada e transnacional. Os Direitos Humanos são o reconhecimento de um patrimônio jurídico mínimo comum para além dos limites geopolíticos do Estado. Muito se discute a respeito da aplicabilidade e da efetivação dos Direitos Humanos, que estão presentes tanto em documentos internacionais quanto no âmbito do direito interno, em forma de norma constitucional. A partir da transnacionalidade, a atuação judicial em perspectiva de troca, é meio para a concretização dos Direitos Humanos, pois um país, ao utilizar o entendimento do outro nos seus casos concretos, apresenta a internacionalização do direito, sem ameaça da segurança jurídica, mas efetivando a pretensão jurídica globalizada e transnacional. Nesta pesquisa, utilizou-se o método indutivo, operacionalizado pela técnica de pesquisa bibliográfica.

PALAVRAS-CHAVE: Direitos Humanos; Dignidade da pessoa humana; Transnacionalidade

\section{ABSTRACT}

This article objects to correlating some aspects of the general agenda of the Human Rights such as transnationality, as the principle of the person's Dignity and with the exchange of legal decision between countries. With no intention to bring answers to the issue, the research identifies Human Right as a union criteria legally considered in globalized society and transnationality. The Human Rights are recognition of a minimum common legal heritage beyond the geopolitical limits of the State. Widely discussed, the applicability and the effectiveness of the Human Rights, present in international and national legal documents, in form of constitutional norms. From the transnationality, the

\footnotetext{
1 Mestranda em Direito, Democracia e Sustentabilidade na Faculdade Meridional - IMED, Passo Fundo - RS. Advogada e Professora do Curso de Direito da Ulbra (Campus Carazinho/RS). E-mail: liegegs@yahoo.com
} 
SOUILLJEE, Liege Giaretta. Direitos Humanos e Transnacionalidade: um debate sobre as pretensões jurídicas globalizadas. Revista Eletrônica Direito e Política, Programa de Pós-Graduação Stricto Sensu em Ciência Jurídica da UNIVALI, Itajaí, v.12, n.3, 30 quadrimestre de 2017. Disponível em: www.univali.br/direitoepolitica - ISSN 1980-7791

judicial action, in a trade perspective, is the way to the completion of the Human Rights, since when a country utilizes the understanding of others on its own specific cases, it presents the internationalization of rights, with no legal security threat, but making the globalized and transnational legal claim effective. The inductive method was used in this research, operationalized by the technique of bibliographic research.

KEYWORDS: Human Rights; Dignity of Human Being; Transnationality

\section{INTRODUÇÃO}

Os Direitos Humanos são objeto de estudo de muitos pesquisadores no mundo, o que permite a compreensão de restrospectivas e perspectivas sobre o tema, sob os mais variados pontos de vista, como por exemplo a efetivação.

Uma das dificuldades encontradas quando se discute sobre a efetivação dos direitos humanos está na dúvida em relação ao critério que será utilizado para sua compreensão, visto que sua aplicabilidade não é igual a todos os sujeitos. Isso implica em questionamento sobre a Dignidade da pessoa humana. Enfoca-se a Dignidade da pessoa humana como critério de união juridicamente considerado e estabelecido entre os indivíduos, sendo que, uma abordagem interdisciplinar é fundamental para se compreender a complexidade da condição de "ser humano" na sociedade globalizada e transnacional.

Os Direitos Humanos compreendem um rol de direitos que são frutos das lutas e conquistas históricas da Humanidade. No decorrer do processo civilizatório, novos direitos estão sendo permanentemente incorporados, de modo que a categoria Direitos Humanos é uma delas que está em constante construção e renovação histórica².

Por este motivo, os Direitos Humanos, como fenomenos históricos, não estão limitados a este ou àquele Estado-nação, mas fazem parte da categoria Humanidade, em qualquer lugar do planeta.

2 Para Bielefeldt: "[...] Os direitos humanos tiveram, e continuam tendo de ser conquistados, também no Ocidente, e isso não só contra as camadas privilegiadas e os avalistas do Estado forte, mas igualmente contra aqueles que viam e vêem ameaçadas as normas tradicionais, as convicções e os relacionamentos de autoridade através das reivindicações emancipacionistas dos modernos direitos humanos". BIELEFELDT, Heiner. Filosofia dos direitos humanos. Tradução de Dankwart Bernsmüller. São Leopoldo, (RS): Editora da UNISINOS, 2000. Título original: Philosophie der menschenrechte, p. 152. 
SOUILLJEE, Liege Giaretta. Direitos Humanos e Transnacionalidade: um debate sobre as pretensões jurídicas globalizadas. Revista Eletrônica Direito e Política, Programa de Pós-Graduação Stricto Sensu em Ciência Jurídica da UNIVALI, Itajaí, v.12, n.3, 30 quadrimestre de 2017. Disponível em: www.univali.br/direitoepolitica - ISSN 1980-7791

Nessa perspectiva, os aportes teóricos apresentados nesta pesquisa buscam identificar o reconhecimento de um patrimônio jurídico mínimo comum, delineado pelo respeito aos Direitos Humanos e Fundamentais, no seu sentido mais amplo, para além dos limites geopolíticos do Estado.

Sem pretensão de apresentar respostas últimas a um tema tão complexo, este artigo objetiva analisar o temário geral dos Direitos Humanos frente às dificuldades de sua concretização, considerando os limites existentes entre organização econômica e social, e buscando um patamar mínimo de igualdade na efetivação destes direitos.

Partindo do pressuposto da Dignidade da pessoa humana, a concretização dos Direitos Humanos não pode ser condicionada apenas ao bem-estar social, às dinâmicas de mercado e ao capitalismo ${ }^{3}$, ao acúmulo de bens, ao aumento da produção e à ampliação das fronteiras comerciais. Esse cenário coloca os seres humanos em condição de desigualdade em níveis consideráveis sendo que, desse modo, sempre haverá uma parte desfavorecida, diante da complexidade da vida humana na sociedade globalizada e transnacional.

No que diz respeito à transnacionalidade, cada vez mais, as pretensões jurídicas estão globalizadas. São questões relacionadas aos Direitos Humanos em âmbito interno e externo, e a utilização do intercâmbio de decisões entre os países materializa-se nas decisões jurídicas em todo o mundo.

É a concepção de pluralismo que auxilia a compreensão dos processos de integração entre Estados, reconhecidos não apenas sob as bases dos interesses do comércio ou da guerra e, sim, sob bases humanistas e éticas. $E$, nesse sentido, busca que sejam reconhecidos os Direitos Humanos de forma igual, supranacional, e globalmente admitidas como uma condição comum.

3 "O capitalismo global está muito mais preocupado em expandir o domínio das relações de mercado do que, por exemplo, em estabelecer a democracia, expandir a educação elementar, ou incrementar as oportunidades sociais para os pobres do mundo. Como a globalização de mercado é, em si mesma, uma abordagem muito inadequada à prosperidade mundial, é preciso ir além das prioridades que encontram expressam no foco escolhido do capitalismo global. SEN, Amartya. As pessoas em primeiro lugar: a ética do desenvolvimento e os problemas do mundo globalizado. Amartya Sem e Bernardo Kliksberg: Tradução Bernardo Ajzemberg, Carlos Eduardo Lins da Silva. São Paulo. Companhia das letras, 2010, p. 28 e 29. 
SOUILLJEE, Liege Giaretta. Direitos Humanos e Transnacionalidade: um debate sobre as pretensões jurídicas globalizadas. Revista Eletrônica Direito e Política, Programa de Pós-Graduação Stricto Sensu em Ciência Jurídica da UNIVALI, Itajaí, v.12, n.3, 30 quadrimestre de 2017. Disponível em: www.univali.br/direitoepolitica - ISSN 1980-7791

importância de uma reflexão sobre os Direitos Humanos e fundamentais como pretensão jurídica comum está em estabelecer o comportamento humano voltado para a Ética, na busca de uma relação abrangente, que garanta o estabelecimento de um padrão de atuação humana coadunado com os valores morais, no sentido de efetivar esses direitos pertencentes a toda humanidade. 0 critério metodológico utilizado para essa pesquisa é o método dedutivo e a técnica de pesquisa é bibliográfica ${ }^{4}$.

\section{ASPECTOS DESTACADOS SOBRE DIREITOS HUMANOS}

Os Direitos Humanos, numa primeira análise, têm como característica principal para sua concretude global a universalidade.

Segundo Grubba, "em sentido oposto, para Arruda Júnior e Golçalves (2004, p. 36), o universalismo nada mais é do que um culturalismo de corte ocidental hegemônico, ou seja, os direitos humanos são justificáveis em razão de sua universalidade, forjada no pensamento iluminista ocidental"5.

Essa discussão sobre a universalidade serve como critério formal que permite o alcance normativo destes direitos numa perspectiva de mundo. Por esse motivo, os Direitos Humanos possuem uma aplicabilidade imediata, em relação ao conjunto de princípios e regras positivados nos ordenamentos jurídicos internos dos territórios nacionais, de forma a evitar os abusos causados pelo exercício do poder do Estado frente ao cidadão ${ }^{6}$.

4 "[...] Técnica de investigação em livros, repertórios jurisprudenciais e coletâneas legais.". PASOLD, Cesar Luiz. Metodologia da pesquisa jurídica. p. 207.

5 GRUBBA, Leilane Serratine. Os direitos humanos como produtos culturais: culturalismo ocidental. In: Revista Arquivo Jurídico. 2015. P. 37. Disponível em: http://www.ojs.ufpi.br/index.php/raj/article/view/4670. Acesso em 11 de junho de 2016.

6 Em complemento, para Garcia: "[...] os direitos humanos surgem na história como reivindicações dos mais débeis os mais fracos serão aqueles que em um esforço de superação irão se unir em torno aos ideais de justiça, liberdade, e igualdade. Se os mais débeis são desunidos ou ignorantes de seus direitos serão fáceis presas dos mais poderosos". GARCIA, Marcos Leite. A declaração universal dos direitos humanos no século XXI: algumas reflexões. In MARCELLINO JÚNIOR, Júlio Cesar, VALLE, Juliano Keller do; AQUINO, Sérgio Ricardo Fernandes de (Orgs.). Direitos fundamentais, economia e estado: reflexões em tempos de crise. Florianópolis: Conceito Editorial, 2010, p. 289. 
SOUILLJEE, Liege Giaretta. Direitos Humanos e Transnacionalidade: um debate sobre as pretensões jurídicas globalizadas. Revista Eletrônica Direito e Política, Programa de Pós-Graduação Stricto Sensu em Ciência Jurídica da UNIVALI, Itajaí, v.12, n.3, 30 quadrimestre de 2017. Disponível em: www.univali.br/direitoepolitica - ISSN 1980-7791

Entretanto, tais Direitos ficam prejudicados pela ausência de uma afinidade entre teoria e prática, pois, em verdade, os Direitos Humanos estão sendo permanentemente violados no mundo da vida. Questiona assim, o papel do Direito, principalmente no que diz respeito à aplicação da lei pelos operadores jurídicos, a nível global.

Outro fator que dificulta a pretendida concretude da universalidade dos Direitos Humanos é a ideia de que os mesmos não se estendem a outro hemisfério, que não seja o ocidental ${ }^{7}$. A sua imposição e proliferação sobre o cenário mundial perpetuam sistemas totalitários ${ }^{8}$ nos quais não existe diálogo que contribua para a pluralidade e diferença alheia no globo.

Os Direitos Humanos oportunizam o diálogo e a aproximação entre os diferentes modos de vida na Terra. O alcance de suas medidas legais e orientação principiológica surgem por meio do desafio de se encontrar em cada vivência cultural algo que nos represente e identifique enquanto humanos. No temário geral dos Direitos Humanos, o ser humano é a fonte de todos os valores.

Considerando as discrepâncias sociais, surgem preocupações com relação ao que se pode fazer para que os menos favorecidos sejam respeitados, promovidos e valorizados em sua Dignidade ${ }^{9}$ humana, em qualquer lugar do globo. A possibilidade de alargamento de suas capacidades e liberdades de escolha, por

7 "[...] enquanto os direitos humanos forem considerados essencialmente uma conquista ocidental, sua aplicação com o objetivo de um reconhecimento mundial deve ser encarada como ilusória ou imperialista". BIELEFELDT, Heiner. Filosofia dos direitos humanos. p. 142.

${ }^{8}$ Segundo Lafer, "[...] O totalitarismo representa uma proposta de organização da sociedade que almeja a dominação total dos indivíduos. Encarna, neste sentido, o processo de ruptura com a tradição, pois não se trata de um regime autocrático, que em contraposição a um regime democrático busca restringir ou abolir as liberdades públicas e as garantias individuais". LAFER, Celso. A reconstrução dos direitos humanos: um diálogo com o pensamento de Hannah Arendt. São Paulo: Companhia das Letras, 1988, p. 117.

9 "Até do final do Século XVIII a Dignidade ainda não estava relacionada com os direitos humanos. De fato, na Declaração Universal dos Direitos do Homem e do Cidadão, de 1789, ela estava entrelaçada com ocupações e posições públicas; nos Estados Unidos, as referências à Dignidade nos Artigos Federalistas, por exemplo, diziam respeito a cargos, ao governo ou a noção como um todo. Portanto, na cultura ocidental, começando com os romanos e chegando até o século XVIII, o primeiro sentido atribuído à Dignidade - enquanto categorização dos indivíduos estava associado a um status superior, uma posição ou classificação social mais alta". BARROSO, Luís Roberto. A Dignidade da pessoa humana direito constitucional contemporâneo. Belo Horizonte: Editora Fórum, 2013, p. 14. 
SOUILLJEE, Liege Giaretta. Direitos Humanos e Transnacionalidade: um debate sobre as pretensões jurídicas globalizadas. Revista Eletrônica Direito e Política, Programa de Pós-Graduação Stricto Sensu em Ciência Jurídica da UNIVALI, Itajaí, v.12, n.3, 30 quadrimestre de 2017. Disponível em: www.univali.br/direitoepolitica - ISSN 1980-7791

meio de princípios de justiça e equidade, traduz um cenário desafiador, a partir do surgimento do Estado de bem-estar social.

Nos últimos séculos, os Estados experimentaram significativas mudanças, notadamente no que tange aos limites de sua intervenção na autonomia do indivíduo e nas relações interprivadas. Tal entendimento, no âmbito nacional, parte dos próprios postulados incorporados pela Constituição de 1988, que institui um modelo de bem-estar atribuindo expressamente ao Estado, em diversas áreas, o dever de atuação direta em prol da realização de direitos fundamentais econômicos e sociais ao cidadão.

Fica instituído que todo ser humano precisa ser amparado minimamente pelo Estado, de forma a viver com o mínimo de Dignidade, no que tange a direitos como educação, saúde, moradia, dentre outros. Cabe ao Estado apresentar a forma como isso será feito, e de que modo a promoção da igualdade material irá concretizar os Direitos Humanos Fundamentais de cunho econômico e social. Preditos direitos têm por objeto a tutela de bens econômicos, sociais e culturais imprescindíveis para assegurar uma vida digna a todos os cidadãos.

Sob esta mesma ótica, a Organização das Nações Unidas define os Direitos Humanos como sendo garantias jurídicas universais ${ }^{10}$, que protegem indivíduos e grupos contra ações ou omissões dos governos que atentem contra a Dignidade Humana. Trata-se de direitos garantidos juridicamente a partir de Declarações universais e de Constituições que os institui. Essa rede de proteção está sustentada num sistema de valores comuns, onde a Dignidade do ser humano, como elemento-chave ${ }^{11}$, obriga os Estados e agentes estaduais a proteger

\footnotetext{
10 Para Grubba: "[...] O discurso das Nações Unidas sobre os direitos humanos, por meio de suas normativas, parece ter se fundamentado em dois pressupostos, o ineretismo e o universalismo, materializando ambos os pressupostos no espaço jurídico. O ineretismo e o universalismo parecem ser pressupostos do próprio nascimento da Organização das Nações Unidas (ONU). A ONU nasce para ser universal e para que suas normativas fossem universais a todos os povos e a todas as pessoas. Além disso, estabelece direitos humanos inerentes e universais, cujo fundamento é a própria inerência da dignidade humana (essência ou característica a priori do humano). GRUBBA, Leilane Serratine. O essencialismo nos direitos humanos. Florianópolis: Empório do Direito, 2016. p. 98.

11 Para Pele: "[...] La Declaración Universal de Derechos Humanos (1948) se abre con el "reconocimiento de la dignidad intrínseca y de los derechos iguales e inalienables de todos los miembros de la familia humana" y varias referencias a la dignidad humana como fundamento de
} 
SOUILLJEE, Liege Giaretta. Direitos Humanos e Transnacionalidade: um debate sobre as pretensões jurídicas globalizadas. Revista Eletrônica Direito e Política, Programa de Pós-Graduação Stricto Sensu em Ciência Jurídica da UNIVALI, Itajaí, v.12, n.3, 30 quadrimestre de 2017. Disponível em: www.univali.br/direitoepolitica - ISSN 1980-7791

indivíduos e grupos em qualquer ordenamento jurídico, pela sua condição de "ser humano".

O Brasil incorporou os Direitos Humanos no texto constitucional de 1988, mais abrangente na tratativa dos direitos fundamentais e que conferiu aos cidadãos brasileiros a titularidade de uma série de posições jurídicas até então inexistente no sistema jurídico pátrio.

Todavia, para além de um Direito posto apenas na letra da lei, buscam-se formas de superar a contradição existente entre a vasta previsão normativa de direitos fundamentais e o baixo grau de efetivação dos mesmos. Indaga-se de que forma - Estado brasileiro, por exemplo, diante de tantos problemas econômicos, políticos e sociais irá concretizar o disposto no artigo $5^{\circ}$ e $6^{\circ}$ da Lei Fundamental. A questão tornou-se ainda mais complexa diante da disposição inscrita no $\S 1^{0}$ do artigo $5^{\circ}$ da Constituição Federal, que preconiza que as normas definidoras dos direitos e garantias fundamentais têm aplicação imediata.

$\mathrm{Na}$ ordem constitucional brasileira, no momento da instituição da República, objetivou-se a formação de uma sociedade livre, justa e solidária ( $C F$, art. 30, I) e pela promoção do bem de todos, sem qualquer tipo de preconceito ( $C F$, art. $3^{0}$, III). Esses termos sintetizam o respeito às concepções pessoais de felicidade e ao livre desenvolvimento da própria personalidade. O ser humano, no contexto brasileiro, pode, no âmbito de um catálogo aberto de direitos fundamentais constitucionalmente tutelados, buscar a concretização do seu bem-estar, vivenciando os valores pessoais que a realizem.

Contudo, as controvérsias sobre os Direitos Humanos decorrem da possibilidade de diversas leituras do conceito, da pluralidade conflituosa de interpretações e concretizações das normas. Nesse ponto, tamanha a diversidade de

los derechos humanos aparecen por ejemplo, en los artículos 1, 22 y 23 . La Convención Americana sobre Derechos Humanos (1969) protege la "dignidad inherente al ser humano" y particularmente en materia de privación de libertad y de protección de la integridad personal (art. 5,6 y 11). Más recientemente, en 2009, la Carta Europea de Derechos Fundamentales dedica su Título I a la "Dignidad" y a la cual vincula cuatro derechos: 1. El derecho a la vida, 2. El derecho a la integridad de la persona, 3. La prohibición de la tortura y de las penas o tratos inhumanos o degradantes, 4. La prohibición de la esclavitud y del trabajo forzado." PELE, Antônio. La dignidad humana: modelo contemporáneo y modelos tradicionales. Revista Brasileira de Direito, v. 11, n. 2, (jul.-dez. 2015). Passo Fundo: IMED, 2015. p. 8 
SOUILLJEE, Liege Giaretta. Direitos Humanos e Transnacionalidade: um debate sobre as pretensões jurídicas globalizadas. Revista Eletrônica Direito e Política, Programa de Pós-Graduação Stricto Sensu em Ciência Jurídica da UNIVALI, Itajaí, v.12, n.3, 30 quadrimestre de 2017. Disponível em: www.univali.br/direitoepolitica - ISSN 1980-7791

possibilidades neste mundo, que os direitos não têm como ser padronizados e instituídos compulsoriamente a todos os países, pois cada região e comunidade possuem características e traços particulares que os identificam, como a questão da cultura e da condição econômica.

Diante destas características, não se pode admitir que a pessoa humana seja um objeto abstrato do discurso normativo dos Direitos Humanos. Se os Direitos Humanos forem analisados sobre o prisma do discurso e da retórica, como artifício jurídico e político, questiona-se qual o seu sentido existencial. Por essa razão, chama-se atenção ao fato de que os Estados nacionais ainda não concretizaram o conteúdo expresso pelos Direitos Humanos e o traduzem como mero sistema normativo dotado de coerção ${ }^{12}$.

Nessa toada, não é exagero dizer que os Direitos Humanos ainda são um desafio no momento presente, pois antigas práticas de violação a direitos estão inseridas na vida cotidiana e observadas pela condição de miserabilidade, de pobreza, de violência, de falta de alimento, de problemas políticos e ambientais e tantos outros. Não por outro motivo que a crise humanitária, que se enfrenta, diz respeito à questão dos migrantes, especialmente no continente europeu.

Em relação a esse tempo, de forma breve, explica-se que o Estranho (alius ${ }^{13}$ ), na pós modernidade, é o refugiado, ou seja, pessoa desprovida de qualquer condição humana e que e, ao mesmo tempo, será alvo de exclusão e segregação. Como falar em Direitos Humanos em cenários como este? São diversos os problemas enfrentados nos países de origem, sendo que, como opção última, os sujeitos são obrigados a migrarem para outros lugares, vítimas diretas

\footnotetext{
12 Para Derrida: "[...] existem, certamente, leis não aplicadas, mas não há lei sem aplicabilidade, e não há aplicabilidade ou 'enforceability' da lei sem força, quer essa força seja direta ou não, física ou simbólica, exterior ou interior, brutal ou sutilmente discursiva - ou hermenêutica - coercitiva, reguladora, etc. Como distinguir entre essa força da lei, essa 'força da lei', como se diz tanto em francês como em inglês, acredito, e por outro lado a violência que julgamos sempre injusta? Que diferença existe entre, por um lado, a força que pode ser justa, em todo caso julgada legítima (não apenas o instrumento a serviço do direito, mas a própria realização, a essência do direito), e, por outro lado, a violência que julgamos injusta? O que é uma força justa ou uma força não violenta?". DERRIDA, Jacques. Força de lei: o fundamento místico da autoridade. Tradução de Leyla PerroneMoisés. São Paulo: Martins Fontes, 2007, p. 9. Título original: Force de loi.
}

13 CORTELLA, Mário Sérgio; TAILLE, Yves de La. Nos labirintos da moral. Campinas, (SP): Papirus, 2005, p. 31. 
SOUILLJEE, Liege Giaretta. Direitos Humanos e Transnacionalidade: um debate sobre as pretensões jurídicas globalizadas. Revista Eletrônica Direito e Política, Programa de Pós-Graduação Stricto Sensu em Ciência Jurídica da UNIVALI, Itajaí, v.12, n.3, 30 quadrimestre de 2017. Disponível em: www.univali.br/direitoepolitica - ISSN 1980-7791

das guerras civis, militares, das crises ambientais, das péssimas condições para desenvolvimento, pela falta de emprego e renda, dentre outros. Trata-se de uma violação à condição humana a retirada das pessoas de seus lares, cidadanias, condições políticas, bem como outros fenômenos, encerrando suas condições de Humanidade num local para se reestruturar em outro. Sobre cidadania, Barreto explica que está:

[...] intimamente vinculada ao processo em devir dos Direitos Humanos que consolidou a Sociedade na modernidade. O conceito de Cidadania surgiu ligado a um ente estatal no século XVIII; seu exercício e realização se fizeram sob a tutela do Estado nacional. Porém, considerando a atual forma de Sociedade, a Cidadania afirma-se pelo envolvimento do cidadão nos movimentos sociais, nos mais diversos, no âmbito da emergente Sociedade civil e esfera pública transnacional que se vai construindo no mundo globalizado ${ }^{14}$.

Todavia, a receptividade não é fraterna. As políticas de controle e segregação apresentam a ideia de que "[...] o estrangeiro não é um cidadão. Ele não tem direitos porque não faz parte do Estado e é um ser humano inferior porque não é cidadão"15. Todavia, Grubba destaca que:

[...] independentemente de nacionalidade, local de residência, sexo, origem nacional ou étnica, cor, religião, língua ou qualquer outra situação, a comunidade internacional assumiu, por meio da Declaração de 1948, o compromisso de defender a dignidade e a justiça para todos, de maneira universal ${ }^{16}$.

A questão dos migrantes, brevemente exposta aqui, é somente mais uma das situações que revelam que os Direitos Humanos ainda carecem de efetivação no plano concreto. Existe uma fragilidade em relação à categoria, e busca-se, como desafio desse século, sustentar práticas sociais, jurídicas e políticas para a concretização dos Direitos Humanos no mundo da vida. A questão dos migrantes,

\footnotetext{
14 BARRETO, Vicente de Paulo. Dicionário de filosofia política. São Leopoldo, RS: Unisinos, 2010, p. 96.

15 DOUZINAS, Costas. O fim dos direitos humanos. Tradução de Luzia Araújo. São Leopoldo, (RS): Editora da UNISINOS, 2009, p. 154.

16 GRUBBA, Leilane Serratine. O essencialismo nos direitos humanos. Florianópolis: Empório do Direito, 2016, p. 102, grifos da autora.
} 
SOUILLJEE, Liege Giaretta. Direitos Humanos e Transnacionalidade: um debate sobre as pretensões jurídicas globalizadas. Revista Eletrônica Direito e Política, Programa de Pós-Graduação Stricto Sensu em Ciência Jurídica da UNIVALI, Itajaí, v.12, n.3, 30 quadrimestre de 2017. Disponível em: www.univali.br/direitoepolitica - ISSN 1980-7791

como objeto de debates internacionais a partir daquilo que é veiculado nos meios de comunicação é apenas a ponta do "iceberg". Dessa forma, a ideia de que os Direitos Humanos servem aos Estados, não às pessoas deve ser enfrentada como medida inicial à superação da crise humanitária. Nesse sentido, a Constituição estatal deve assegurar a Dignidade humana não só aos nacionais, mas a todos aqueles que, como pessoa, transitam pelo seu espaço.

\section{A TRANSNACIONALIDADE E OS DIREITOS HUMANOS COMO PATRIMÔNIO JURÍDICO COMUM}

No temário geral dos Direitos Humanos, percebe-se que os desafios a serem enfrentados são inúmeros e exigem uma atuação conjunta de Estado e sociedade global no sentido de buscar novas possibilidades à categoria.

Em virtude das interações humanas estarem cada vez mais integradas pela mundialização, os fenômenos da globalização e da transnacionalidade contribuíram de forma significativa para a integração mundial, nos mais variados aspectos. Para Cruz, a transnacionalidade é um mundo novo, uma espécie de continente não investigado que se abre a uma terra de ninguém transnacional, a um espaço intermediário entre o nacional e o local ${ }^{17}$.

Pretensões jurídicas globalizadas, nesse ponto, dizem respeito aos Direitos Humanos em âmbito interno e externo. É a concepção de pluralismo que auxilia na compreensão dos processos de integração entre Estados, reconhecidos não apenas sob as bases dos interesses bélicos ou de mercado, mas sim, sob os Direitos Humanos. Não se pode fechar os olhos para os novos cenários jurídicos globais, que sinalizam para o intercâmbio, a integração e a troca, sem, contudo, desestabilizar sistema jurídico ou vigente ou ameaçar a segurança jurídica já existente. Logo:

[...] a construção de novos espaços a partir da perspectiva de ampliação da esfera da influência da experiência das Sociedades democráticas para além das fronteiras nacionais. [...] pelos caminhos de uma política interna voltada para o

17 CRUZ, Paulo Márcio. Da Soberania à Transnacionalidade: Democracia, direito e Estado no século XXI. Itajaí, (SC): Editora da UNIVALI, 2011, p. 148. 
SOUILLJEE, Liege Giaretta. Direitos Humanos e Transnacionalidade: um debate sobre as pretensões jurídicas globalizadas. Revista Eletrônica Direito e Política, Programa de Pós-Graduação Stricto Sensu em Ciência Jurídica da UNIVALI, Itajaí, v.12, n.3, 30 quadrimestre de 2017. Disponível em: www.univali.br/direitoepolitica - ISSN 1980-7791

mundo em geral, ou seja, aberta a uma ordem jurídica cosmopolita, capaz de funcionar sem a estrutura de um governo mundial18.

A partir do fenômeno da transnacionalidade e admitidos diversos entendimentos nesse sentido, chama-se atenção ao diálogo que existe entre os supremos tribunais ou cortes constitucionais, que invocam precedentes jurisprudenciais de outras cortes estrangeiras e de tribunais para a resolução de suas demandas. Isso demonstra o quanto as pretensões jurídicas estão globalizadas, mas também, o quanto a resolução destas demandas exige novas posturas na sociedade atual.

Constata-se um cenário de troca na inclusão, cada vez mais frequente, nas razões de decidir, de produções diversas sobre direito internacional e decisões oriundas dos mais variados países. Tribunais constitucionais e cortes supremas de todo o mundo começaram a se engajar em um crescente diálogo constitucional envolvendo citação mútua, conferências de intercâmbio acadêmico e organização de fóruns públicos como a Comissão de Veneza19. Assim, os juízes adquirem uma liberdade e autonomia muito maior, não no sentido da discricionariedade arbitrária, mas sim, no exercício de direito comparado em relação ao tratamento das questões de Direitos Humanos e fundamentais, aplicando, no plano da jurisdição interna, os tratados e convenções firmados pelos Estados a que estão vinculados ${ }^{20}$. Não por outro motivo, nos Estados Unidos, a "atenção ao julgamento de outras nações" foi recomendada ${ }^{21}$. Sob a mesma linha de pensamento, Barroso destaca que:

Sociedades plurais e altamente complexas se deparam com desafios em áreas que vão desde a segurança nacional até questões religiosas, raciais e sexuais. Controvérsias, ideias, argumentos jurídicos, interferência morais e propostas de

\footnotetext{
18 GARCIA, Marcos Leite. Direitos fundamentais e Transnacionalidade: um estudo preliminar. In: CRUZ, Paulo Márcio. STELZER, Joana. Direito e Transnacionalidade. Curitiba: Juruá, 2011 , p. 173.

19 BARROSO, Luís Roberto. A Dignidade da pessoa humana direito constitucional contemporâneo. p. 34.

20 GARAPON, Antonie; ALLARD, Julie. Os juízes na mundialização. A nova revolução do direito. Tradução Rogério Alves: Lisboa: Instituto Piaget, 2006, p. 12.

21 GARAPON, Antonie; ALLARD, Julie. Os juízes na mundialização.p. 12.
} 
SOUILLJEE, Liege Giaretta. Direitos Humanos e Transnacionalidade: um debate sobre as pretensões jurídicas globalizadas. Revista Eletrônica Direito e Política, Programa de Pós-Graduação Stricto Sensu em Ciência Jurídica da UNIVALI, Itajaí, v.12, n.3, 30 quadrimestre de 2017. Disponível em: www.univali.br/direitoepolitica - ISSN 1980-7791

soluções são similares e recorrentes por todo o mundo, e as visões e percepções dos juízes de um país podem enriquecer o raciocínio juízes de outras jurisdições. Decisões judiciais estrangeiras podem oferecer novas informações e perspectivas, e também ajudar na construção de consensos. Parece ser esse o caso em relação à pena de morte (com exceção dos Estados Unidos) e, em alguma medida, também ao aborto (Estados Unidos, Alemanha, França e Canadá, entre outros, possuem legislação similar nesta matéria). Como intuitivo e fora de qualquer dúvida, as decisões judiciais estrangeiras têm apenas uma autoridade persuasiva, não sendo vinculante. Somente esse fato já seria suficiente para afastar qualquer espécie de temor provinciano. Em determinadas ocasiões, a abordagem comparativa pode ser utilizada por votos divergentes, para demonstrar como razoes locais, culturais, sociais ou política deveriam levar a soluções diferentes ${ }^{22}$.

A abertura a este fenômeno de transnacionalidade nas decisões pode ser observada, também, nas decisões de outras Cortes Supremas nacionais, como, por exemplo, a Corte Suprema da África do Sul ao se referir a julgamentos da Corte dos Estados Unidos, da Suprema Corte do Canadá, e do Tribunal Constitucional da Alemanha.

Com efeito, julgamentos que envolvem questões sobre Direitos Humanos são bastante propícios para essa modalidade de comunicação jurisdicional, numa perspectiva planetária. Na África do Sul, a Corte Constitucional tem citado diversas decisões da Suprema Corte do Canadá, em casos envolvendo o direito das mulheres à igualdade, como justificativa de que discriminações injustas violam a Dignidade humana individual ${ }^{23}$.

$\mathrm{Na}$ Inglaterra há um claro indicativo da busca de valores constitucionais de outros países democráticos, especialmente quando dizem respeito aos Direitos Humanos. Seguindo a transnacionalidade, para Neves ${ }^{24}$, o intercâmbio é um forte indício de que esse país está aberto ao diálogo "transconstitucional". Muito

22 BARROSO, Luís Roberto. A dignidade da pessoa humana direito constitucional contemporâneo. p. 35.

23 BARROSO, Luís Roberto.

A Dignidade da pessoa humana direito constitucional contemporâneo. p. 37.

24 NEVES, Marcelo. Transconstitucionalismo. São Paulo: Martins Fontes, 2009, p. 177. 
SOUILLJEE, Liege Giaretta. Direitos Humanos e Transnacionalidade: um debate sobre as pretensões jurídicas globalizadas. Revista Eletrônica Direito e Política, Programa de Pós-Graduação Stricto Sensu em Ciência Jurídica da UNIVALI, Itajaí, v.12, n.3, 30 quadrimestre de 2017. Disponível em: www.univali.br/direitoepolitica - ISSN 1980-7791

mais do que vínculos meramente normativos, este fenômeno denota uma reserva de interpretação em favor de um patrimônio jurídico comum no compartilhamento de valores pela comunidade internacional, onde a base é, por certo, os Direitos Humanos.

Por força destes fenômenos, como resultado dos processos de globalização e mundialização, o discurso de um patrimônio jurídico comum é sustentado diante das pretensões jurídicas que estão, atualmente, globalizadas. Por esta razão, o Direito, como fenômeno cultural e social, produto das interações humanas, não é um Direito de "olhos fechados" 25. As ordens jurídicas, em comunhão e compartilhamento, podem encontrar soluções definitivas e cabais aos mesmos problemas jurídicos constitucionais de Direitos Humanos.

Os Direitos Humanos, positivados na Constituição, são complementados por outros valores, pelo respeito à autonomia e à consciência individual de cada pessoa. O Estado deve atentar ao respeito à Dignidade da pessoa humana, como patrimônio jurídico mínimo, independente de sua nacionalidade e de qual o estado de atuação desse sujeito. Para tanto, refletir a respeito de políticas públicas, da receptividade dos migrantes e das condições de igualdade e oportunidade para crescimento pessoal estão no cerne da discussão. Como ser humano, dotado de liberdade e autonomia, precisa-se rever os modelos de desenvolvimento, as dinâmicas de mercado, os impactos da atuação humana no meio ambiente, a lógica capitalista do consumo exacerbado e tantas outras situações que exigem uma reflexão no momento presente. Estas situações sinalizam implicações diretas à Dignidade do ser humano no plano terrestre.

Os Direitos Humanos estão em processo de evolução de forma constante. Não há como interromper a lógica de expansão destes direitos, se considerados como conquistas históricas que estão, em verdade, ocorrendo na vida de todos os dias. Os Direitos Humanos vão acumulando-se e sustentando um rol balizado pelo princípio da Dignidade da pessoa humana. Numa perspectiva globalizada e transnacional, buscam-se novos instrumentos e mecanismos para garantir a

25 CUNHA, Paulo Ferreira. Constituição viva: cidadania e Direitos Humanos. Porto Alegre: Livraria do Advogado, 2007, p. 61. 
SOUILLJEE, Liege Giaretta. Direitos Humanos e Transnacionalidade: um debate sobre as pretensões jurídicas globalizadas. Revista Eletrônica Direito e Política, Programa de Pós-Graduação Stricto Sensu em Ciência Jurídica da UNIVALI, Itajaí, v.12, n.3, 30 quadrimestre de 2017. Disponível em: www.univali.br/direitoepolitica - ISSN 1980-7791

eficácia universal dos Direitos Humanos para além de discurso político e de retórica social. Não se trata de mitigar o princípio da soberania, na autodeterminação dos povos ou da segurança jurídica, mas sim, ampliar o debate e o alcance dos Direitos Humanos a partir da transnacionalidade.

Dessa forma, é possível que adentrem em ordenamentos jurídicos diversos e especificamente, no ordenamento jurídico pátrio, as convenções e tratados de Direitos Humanos que foram incorporados pela Constituição Federal. Contudo, o campo de incidência dos Direitos Humanos extrapola os limites nacionais no tocante à atuação jurisdicional, e atua, a partir de seu caráter de essencialidade, como patrimônio jurídico comum a todos os países.

A priori, uma atuação jurisdicional, nesse sentido, identifica os Direitos Humanos como direitos internacionalizados e com uma carga valorativa compartilhada, qual seja, a Dignidade da pessoa humana. Assim, não há espaço para situações de tensionamento na invocação deste ou daquele julgado sobre o tema, pois, em sua essência, o que está sendo tutelado é a condição humana e sua dignidade nos mais diversos ordenamentos jurídicos. Espaços geopolíticos delimitados não são impedimentos para o intercâmbio de decisões judiciais, visto que, pretensões jurídicas globalizadas são uma característica do Direito nesse século. Como temário que interessa à comunidade internacional, cabe destacar que, para Staffen:

[...] a Globalização jurídica necessita fazer frente a problemas diversos, tais como conflitos de uniformidade e diferenças nacionais, a concorrência de normas globaisnacionais-locais, a atribuições de competências, a regulação do capital e nortes para governança global, a promoção dos Direitos Humanos, a preservação ambiental e critérios de Sustentabilidade planetária, o combate de redes criminosas, enfim, uma nova e eficaz forma de limitação de um poder de extrema fluidez, como é a ordem global atual. Por derradeiro, o paradigma de Direito Global que se anuncia promove elementos válidos para uma oxigenação consistente e atualizada dos ideais de direito humanos, Democracia e Sustentabilidade. Potencial este que dificilmente materializar-se-ia em cenários de onipotência estatal, isto é, possibilita-se a substancial vivência democrática, humanitária e sustentável para além do 
SOUILLJEE, Liege Giaretta. Direitos Humanos e Transnacionalidade: um debate sobre as pretensões jurídicas globalizadas. Revista Eletrônica Direito e Política, Programa de Pós-Graduação Stricto Sensu em Ciência Jurídica da UNIVALI, Itajaí, v.12, n.3, 30 quadrimestre de 2017. Disponível em: www.univali.br/direitoepolitica - ISSN 1980-7791

Estado. Afinal, ainda é este, o Estado, o grande demandado por violações aos Direitos Humanos, supressão de faculdades democráticas e travejamento à Sustentabilidade... ${ }^{26}$.

Conforme demonstrado, a dimensão jurídica possui um alcance além do Estado, de modo que é imprescindível considerar realidades culturais, locais, ou historicamente constituídas, no momento da aplicação do Direito ${ }^{27}$. A integração jurídica apresenta soluções efetivas para realidades jurídicas globais compartilhadas. Sob esse viés, novos espaços de juridicidade surgem para sustentar novos modelos jurídicos a respeito da tutela de bens e interesses comuns, como é o caso dos Direitos Humanos. Trata-se de uma reivindicação humanizadora pela construção dos Direitos Humanos na vida cotidiana.

\section{CONSIDERAÇÕES FINAIS}

A temática geral dos Direitos Humanos está no centro do debate da ciência jurídica em virtude da sua importância para a concretização do princípio da dignidade da pessoa humana. Muito se discute a respeito da aplicabilidade e da efetivação dos Direitos Humanos que estão presentes tanto em documentos internacionais quanto no âmbito do direito interno, em forma de norma constitucional. Questiona-se o porquê dos Direitos Humanos estarem sendo concretizados para umas pessoas e não para outras, e essa pergunta é alvo de dicussão em todo o globo.

Conclui-se que o princípio da Dignidade é o critério de união juridicamente considerado e estabelecido entre os seres humanos, sendo que, uma abordagem interdisciplinar é fundamental para se compreender a complexidade da condição de "ser humano" na sociedade globalizada e transnacional.

Nesta pesquisa identificou-se o reconhecimento de um patrimônio jurídico mínimo comum, delineado pelo respeito aos Direitos Humanos e Fundamentais, para além dos limites geopolíticos do Estado. Essa condição atinge os

${ }^{26}$ STAFFEN, Márcio Ricardo. Interfaces do Direito Global. Rio de Janeiro: Lumen Juris, 2015, p. 41 .

27 SANTOS, Boaventura; GARCÍA VILLEGAS, Maurício. El caledoscopio de las Justicias em Colômbia. Bogotá: Siglo del Hombre Editores, 2001, p. 145. 
SOUILLJEE, Liege Giaretta. Direitos Humanos e Transnacionalidade: um debate sobre as pretensões jurídicas globalizadas. Revista Eletrônica Direito e Política, Programa de Pós-Graduação Stricto Sensu em Ciência Jurídica da UNIVALI, Itajaí, v.12, n.3, 30 quadrimestre de 2017. Disponível em: www.univali.br/direitoepolitica - ISSN 1980-7791

estrangeiros e as pessoas em situação de migração, ainda que transitem temporariamente no país.

A partir da transnacionalidade, a atuação judicial em perspectiva de troca, é meio para a concretização dos Direitos Humanos, pois um país, ao utilizar o entendimento do outro, nos seus casos concretos, apresenta a internacionalização do direito, sem ameaça da segurança jurídica, mas efetivando a pretensão jurídica globalizada e transnacional.

\section{REFERÊNCIAS BIBLIOGRÁFICAS}

BARROSO, Luís Roberto. A Dignidade da pessoa humana direito constitucional contemporâneo. Belo Horizonte: Editora Fórum, 2013.

BIELEFELDT, Heiner. Filosofia dos direitos humanos. Tradução de Dankwart Bernsmüller. São Leopoldo, (RS): Editora da UNISINOS, 2000. Título original: Philosophie der menschenrechte

CORTELLA, Mário Sérgio; TAILLE, Yves de La. Nos labirintos da moral. Campinas, (SP): Papirus, 2005.

CUNHA, Paulo Ferreira. Constituição viva: cidadania e Direitos Humanos. Porto Alegre: Livraria do Advogado, 2007.

DERRIDA, Jacques. Força de lei: o fundamento místico da autoridade. Tradução de Leyla Perrone-Moisés. São Paulo: Martins Fontes, 2007. Título original: Force de loi.

DOUZINAS, Costas. O fim dos direitos humanos. Tradução de Luzia Araújo. São Leopoldo, (RS): Editora da UNISINOS, 2009.

GARAPON, Antonie; ALLARD, Julie. Os juízes na mundialização. A nova revolução do direito. Tradução Rogério Alves: Lisboa: Instituto Piaget, 2006.

GARCIA, Marcos Leite. Direitos fundamentais e Transnacionalidade: um estudo preliminar. In: CRUZ, Paulo Márcio. STELZER, Joana. Direito e Transnacionalidade. Curitiba: Juruá, 2011, p. 173.

GARCIA, Marcos Leite. A declaração universal dos direitos humanos no século XXI: algumas reflexões. In MARCELLINO JÚNIOR, Júlio Cesar, VALLE, Juliano Keller do; AQUINO, Sérgio Ricardo Fernandes de (Orgs.). Direitos fundamentais, economia e estado: reflexões em tempos de crise. Florianópolis: Conceito Editorial, 2010.

GRUBBA, Leilane Serratine. O essencialismo nos direitos humanos. Florianópolis: Empório do Direito, 2016. 
SOUILLJEE, Liege Giaretta. Direitos Humanos e Transnacionalidade: um debate sobre as pretensões jurídicas globalizadas. Revista Eletrônica Direito e Política, Programa de Pós-Graduação Stricto Sensu em Ciência Jurídica da UNIVALI, Itajaí, v.12, n.3, 30 quadrimestre de 2017. Disponível em: www.univali.br/direitoepolitica - ISSN 1980-7791

GRUBBA, Leilane Serratine. Os direitos humanos como produtos culturais: culturalismo ocidental. In: Revista Arquivo Jurídico. 2015. Disponível em: http://www.ojs.ufpi.br/index.php/raj/article/view/4670. Acesso em 11 de junho de 2016.

LAFER, Celso. A reconstrução dos direitos humanos: um diálogo com o pensamento de Hannah Arendt. São Paulo: Companhia das Letras, 1988.

PASOLD, Cesar Luiz. Metodologia da pesquisa jurídica: teoria e prática. 12. ed. São Paulo: Conceito Editorial, 2011.

SEN, Amartya. As pessoas em primeiro lugar: a ética do desenvolvimento e os problemas do mundo globalizado. Amartya Sem e Bernardo Kliksberg: Tradução Bernardo Ajzemberg, Carlos Eduardo Lins da Silva. São Paulo. Companhia das letras, 2010.

STAFFEN, Márcio Ricardo. Interfaces do Direito Global. Rio de Janeiro: Lumen Juris, 2015.

WARAT, Luis Alberto. Introdução geral ao direito II: a epistemologia jurídica da modernidade. Tradução de José Luiz Bolzan. Porto Alegre: Sérgio Antônio Fabris, 1995, p. 67-68.

Submetido em: maio de 2017

Aprovado em: agosto de 2017 